\title{
Áreas protegidas na Amazônia mato-grossense: riscos e desafios à conservação e preservação
}

\section{Protected areas in the Amazônia mato-grossense: risks and challenges to the conservation and preservation}

Carlos Teodoro José Hugueney Irigaray - Ph.D. em Direito Ambiental; professor associado e coordenador do Programa de Pós-Graduação em Direito Agroambiental da Universidade Federal de Mato Grosso (UFMT), Cuiabá-MT, Brasil. E-mail: teodoro.irigaray@gmail.com

Carolina Joana da Silva - Ph.D. Ecologia e Conservação de Áreas Úmidas do Pantanal; professora da Universidade do Estado de Mato Grosso. (UNEMAT), Cuiabá-MT, Brasil. E-mail: ecopanta@ terra.com.br

Josué Ribeiro da Silva Nunes - Doutor em Ecologia e Recursos Naturais; professor da Universidade do Estado de Mato Grosso (UNEMAT), Cuiabá-MT, Brasil. E-mail: josue@unemat.br

Heitor Queiróz de Medeiros - Doutor em Ecologia e Recursos Naturais; professor visitante da Universidade do Estado de Mato Grosso (UNEMAT), Cuiabá-MT, Brasil.

E-mail: medeiros.heitor@gmail.com

Daniela Paes de Barros - Advogada, mestre em Direito Agroambiental da Faculdade de Direito Universidade Federal de Mato Grosso (UFMT), Cuiabá-MT, Brasil. E-mail: danielapb@terra.com.br

Nilo Leal Sander - Mestre em Ciências Ambientais Universidade do Estado de Mato Grosso (UNEMAT), Cuiabá-MT, Brasil. Trabalha atualmente com etnobiologia e ecologia vegetal. E-mail: nilosander@gmail.com

\section{Resumo}

A Amazônia caracteriza-se como um mosaico dotado de megadiversidade, no qual estão abrigadas inúmeras categorias de áreas especialmente protegidas, com características e problemas diferenciados. Neste artigo são enfocados os riscos e desafios à conservação e preservação dessas áreas, localizadas no estado de Mato Grosso, através da análise dos problemas que enfrentam e dos conflitos socioambientais associados à sua implantação e gestão. Essa abordagem jurídica é complementada pelo exame das políticas públicas voltadas para a preservação e conservação dessas áreas e do exame dos principais problemas socioambientais que as atingem, e eventualmente as impedem de alcançar o seu objetivo precípuo de conservação.

\section{Palavras-chave}

Áreas protegidas. Políticas públicas. Gestão ambiental.

\begin{abstract}
The Amazon is characterized as a mosaic endowed with megabiodiversity, in which there are numerous categories of specially protected areas with different characteristics and problems. In this article we focused on the risks and challenges to conservation and preservation of these areas, located in the Mato Grosso State, through the analysis of the problems faced and environmental conflicts associated with their deployment and management. This legal approach is complemented by an examination of public policies for the preservation and conservation of these areas and examine the main social problems that affect them and eventually prevent them from doing their primary purpose of conservation.
\end{abstract}

\section{Keywords}

Protected areas. Public Policy. Environmental management. 


\section{INTRODUÇÃO}

Situado ao sul do Planalto das Guianas, a norte do Planalto Central, a leste da Cordilheira dos Andes e a oeste do Oceano Atlântico, drenando, além do Brasil, terras de oito países sul-americanos (DIEGUES, 2002), esse bioma

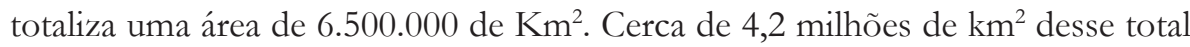
encontra-se no Brasil, na bacia amazônica, distribuídos entre os estados do Acre, Amazonas, Roraima, Pará, Amapá e Rondônia (Região Norte) e a porção norte e noroeste do estado de Mato Grosso (Região Centro-Oeste), representando 49\% do território nacional (IBGE, 2010).

Além da riqueza natural, a Amazônia abriga uma fantástica diversidade cultural, onde vivem cerca de 170 povos indígenas, com uma população aproximada de 180 mil indivíduos, 357 comunidades remanescentes de antigos quilombolas e milhares de comunidades de castanheiros, ribeirinhos, babaçueiras, entre outras. Este patrimônio socioambiental brasileiro chegou ao ano $2000 \mathrm{com}$ suas características originais relativamente bem preservadas. Ainda é possível contabilizar pelo menos 50 grupos indígenas arredios e sem contato regular com o mundo exterior (CAPOBIANCO, 2001).

Nesse contexto, tem-se a unidade administrativa conhecida por Amazônia Legal Brasileira, formada pelos estados do Acre, Amapá, Amazonas, Pará, Rondônia, Roraima, Tocantins, Mato Grosso e parte do Maranhão (a oeste do meridiano $44^{\circ} \mathrm{W}$ ), tendo sido estabelecida inicialmente pela Lei Federal $n^{\circ} 5.173$, de 27 de outubro de 1966 (art. $2^{\circ}$ ), com posteriores alterações. O Mato Grosso veio a integrar este território com o art. 45 da Lei Complementar Federal no 31, de 11 de outubro de 1977, e posteriormente o estado do Tocantins, criado através das Disposições Transitórias da Constituição Federal (art. 13), em outubro de 1988.

Com uma área de mais de 5 milhões de quilômetros quadrados (dois terços do Brasil), a Amazônia Legal engloba todo o bioma Amazônico localizado no Brasil, 37\% do Cerrado e 40\% do bioma Pantanal, e é caracterizada por um mosaico de ecossistemas com significativas diferenças tanto em termos de estrutura e interações de comunidades e populações naturais, quanto em ocorrência e abundância de espécies da flora, fauna, fungos e microbiota (ISA, 2009). Representando 59\% do território brasileiro e 775 municípios, a Amazônia Legal congrega aproximadamente 24,7 milhões de habitantes (IBGE, 2010), dentre os quais mais de 250 mil indígenas pertencentes a mais de 170 etnias (VERÍSSIMO et al., 2011) e diversas comunidades extrativistas tradicionais, como seringueiros, castanheiros, pescadores artesanais, quebradeiras de coco de babaçu, dentre outras.

Novos Cadernos NAEA, v. 16, n. 1, Suplemento, p. 221-246, jun. 2013 
Em especial, o estado de Mato Grosso, localizado no coração da América do Sul, tem uma área de 903.329,700 km², com 3.035.122 habitantes (IBGE. 2010), que engloba a biodiversidade de três grandes biomas brasileiros: a Amazônia, o Cerrado e o Pantanal Mato-grossense. Entre estes três biomas, a Amazônia é o mais abrangente, com 480.215,00 km² (53,6\%); o Cerrado ocupa $354.823,00 \mathrm{~km}^{2}(39,6 \%)$ e a menor área é do Pantanal, com $60.885,00 \mathrm{~km}^{2}(6,8 \%)$.

Estima-se que a Amazônia brasileira possui a maior riqueza de espécies vegetais e animais, aproximadamente 15\% dos 1,5 milhões de espécies já catalogadas existentes no planeta. São cerca de $22 \%$ das espécies de plantas com sementes, $10 \%$ das espécies de mamíferos, 17\% das aves, 15\% dos anfíbios e 10\% de todas as espécies de peixes (CASTRO, 1998; BICUDO; SHEPHERD, 1998).

Além dessa expressiva diversidade biológica, o bioma Amazônia exerce uma função primordial para a existência e manutenção da nossa espécie, pelas suas funções e serviços ecológicos prestados pelos seus ecossistemas, como a manutenção do ciclo do carbono e, consequentemente, a regulação do clima, mitigando o aquecimento global; funcionando como barreiras para grandes incêndios devido à umidade mantida pela evapotranspiração; no controle da vazão das bacias hidrográficas da região, na recarga do lençol freático, no controle da inundação, retenção e transporte de sedimentos e nutrientes; no controle da erosão; na produção de matérias-primas e recursos genéticos; fatores estes que justificam a necessidades de sua conservação ${ }^{1}$.

A Convenção da Diversidade Biológica (CDB) refere-se à biodiversidade como a abundância e variabilidade dentro e entre todas as formas, níveis e variações de organismos vivos, incluindo três níveis de abordagem: diversidade dentro da espécie ou genética, diversidade entre espécies e a diversidade de ecossistemas. A diversidade genética é entendida como toda a informação genética de cada espécie individual. A diversidade de espécies refere-se à frequência e variação de diferentes organismos, e a diversidade de ecossistemas engloba a variação no habitat e na comunidade, assim como de processos ecológicos do ecossistema. Segundo Willink, uma definição operacional de biodiversidade é a quantidade e composição de entidades vivas em diferentes escalas, espacial e organizacional (WILLINKet al., 2000).

O estabelecimento de uma política, tal como proposta na Convenção da Diversidade Biológica, pressupõe uma avaliação da biodiversidade em

\footnotetext{
Para introduzir o ambiente amazônico, usaremos o conceito de bioma utilizado por Felfili, que se refere a uma subdivisão biológica da superfície terrestre que reflete o caráter ecológico e fisionômico da vegetação, e que corresponde aproximadamente com as regiões climáticas, embora outros fatores ambientais possam ser importantes (FELFILI, 2002).
} 
ambas escalas: regional e nacional, além da formulação de estratégias para a sua conservação. Neste sentido, o governo brasileiro organizou o Programa Nacional de Biodiversidade (PRONABIO), o qual está desenvolvendo as políticas públicas visando à organização da base de dados existentes e as recomendações para a proteção dos principais biomas brasileiros (DA SILVA; RYLANDS; PATTON, 2001). Dentre as ações implementadas no âmbito dessas políticas, insere-se a criação de áreas protegidas, como forma de assegurar a manutenção de mostras significativas dos ecossistemas existentes.

Nessa mesma perspectiva, a Constituição Federal definiu como uma tarefa atribuída ao poder público, o estabelecimento de espaços territoriais e de áreas especialmente protegidas, visando assegurar a efetividade do direito ao meio ambiente sadio e equilibrado. Essa tarefa envolve, entre outras medidas, a criação de unidades de conservação, a qual se efetiva nos termos da Lei no 9.985/2000, que dispõe sobre a Política Nacional de Unidades de Conservação, além de um amplo rol de normas que apoiam a proteção dessas áreas.

Nesta abordagem serão examinadas as áreas legalmente protegidas, localizadas na Amazônia mato-grossense, assim considerada a área total ou parcialmente coberta originalmente pela floresta amazônica, que abrange cerca de 141 municípios. Nessas unidades, caracterizadas por uma megadiversidade, estão abrigadas inúmeras categorias de áreas legalmente protegidas. Analisar os riscos e desafios à conservação e preservação dessas áreas implica necessariamente a abordagem do marco regulatório no qual se fundamenta a criação dessas áreas e na identificação dos problemas que enfrentam, e dos conflitos socioambientais associados à sua implantação e gestão.

Assim, embora o arcabouço legal existente no país para proteger a flora seja vasto, pergunta-se se, de fato, essa proteção existe para a floresta amazônica localizada em Mato Grosso e se as políticas públicas e os instrumentos legais são suficientes ou eficientes para a consecução desse fim.

\section{AS ÁREAS LEGALMENTE PROTEGIDAS}

A Constituição Federal reconhece o direito ao meio ambiente sadio e equilibrado como um direito fundamental, impondo, sobretudo ao poder público, um elenco de tarefas, visando à concretização desse direito.

Conforme assinalado, dentre as tarefas constitucionalmente atribuídas ao poder público insere-se a definição de espaços territoriais e seus componentes a serem especialmente protegidos. O preceito que estabelece essa atribuição (CRB:

Novos Cadernos NAEA, v. 16, n. 1, Suplemento, p. 221-246, jun. 2013 
Art. $225 \int 1^{\circ}$, III) determina também que a alteração e a supressão dessas áreas somente serão permitidas mediante lei, vedando, ainda, qualquer utilização que comprometa a integridade dos atributos que justifiquem a sua proteção.

Ainda no mesmo dispositivo, a Constituição considerou como patrimônio nacional algumas áreas que devem ter a proteção especialmente assegurada pela lei, inserindo-se entre elas a floresta amazônica (CRB: Art. 225, \4 $4^{\circ}$ ).

Irigaray (2004) observa que a referência constitucional aos espaços territoriais protegidos abrange inúmeras categorias de proteção legal e limitações administrativas que não se cingem às conhecidas unidades de conservação, assinalando:

Dentre os espaços territoriais protegidos, apenas na esfera federal, inserem-se, além das já mencionadas, as áreas de patrimônio nacional, terras indígenas, áreas de preservação permanente, áreas de reserva legal, paralelogramo de cobertura vegetal, terrenos de Marinha, e terrenos marginais, entre outros (IRIGARAY, 2004, p.81-91).

Nesse mesmo sentido, a ponderação de propósito, segundo José Afonso da Silva:

Nem todo espaço territorial especialmente protegido se confunde com unidade de conservação, mas estas são também espaços especialmente protegidos. Não é fácil, porém, diante da legislação em vigor, dizer quando um espaço territorial especialmente protegido deve ser considerado unidade de conservação. O máximo que se pode dizer é que um espaço territorial se converte numa unidade de conservação, quando assim declarado expressamente, para lhe atribuir um regime jurídico mais restritivo e mais determinado (SILVA, 1994).

A legislação infraconstitucional regulamenta a proteção dessas áreas, cuja utilização deve se dar de forma diferenciada. Dentre os diplomas legais que normatizam a matéria destaca-se o chamado novo Código Florestal, instituído pela Lei nº 12.651/2012, que protege as Áreas de Preservação Permanente (APPs), definidas como aquela área protegida, coberta ou não por vegetação nativa, com a função ambiental de preservar os recursos hídricos, a paisagem, a estabilidade geológica, a biodiversidade, o fluxo gênico de fauna e flora, proteger o solo e assegurar o bem-estar das populações humanas (art. $3^{\circ}$, II).

$\mathrm{Na}$ sequência, como área de proteção legal, tem-se a reserva legal, assim considerada a área localizada no interior de uma propriedade ou posse rural, com a função de assegurar o uso econômico de modo sustentável dos recursos naturais do imóvel rural, assegurar a conservação e reabilitação dos processos ecológicos, e promover a conservação da biodiversidade, bem como o abrigo e proteção de fauna e flora nativas (Lei nº 12.651/2012: Art. $3^{\circ}$, III). 
Também são áreas especialmente protegidas as terras indígenas, que, segundo levantamento da Secretaria de Planejamento do Estado de Mato Grosso, em 2009 totalizavam 68, e que não serão objeto desta análise, face as suas peculiaridades, que demandariam um estudo específico.

Nesta abordagem serão considerados apenas os limites e desafios à proteção de uma categoria específica de área protegida, as Unidades de Conservação. De acordo com o Sistema Nacional de Unidades de Conservação (SNUC; Lei n ${ }^{\circ}$ 9.985/2000), essas áreas instituídas e geridas pelo poder público federal, estadual ou municipal, integram dois grupos, com características específicas: Unidades de Proteção Integral, cujo objetivo básico é preservar a natureza, sendo admitido apenas o uso indireto dos seus recursos naturais, com exceção dos casos previstos na Lei; e Unidades de Uso Sustentável, com objetivo de compatibilizar a conservação da natureza com o uso sustentável de parcela dos seus recursos naturais $\left(\operatorname{art.} 7^{\circ}\right)$.

O grupo das Unidades de Proteção Integral é composto pelas seguintes categorias de unidades de conservação: Estação Ecológica; Reserva Biológica; Parque Nacional; Monumento Natural e Refúgio de Vida Silvestre (art. 8º. Já o Grupo das Unidades de Uso Sustentável abrange as seguintes categorias de unidade de conservação (art. 14): Área de Proteção Ambiental (APA); Área de Relevante Interesse Ecológico; Floresta Nacional; Reserva Extrativista; Reserva de Fauna; Reserva de Desenvolvimento Sustentável e Reserva Particular do Patrimônio Natural (RPPN) ${ }^{2}$.

No que concerne ao Código Estadual do Meio Ambiente do estado de Mato Grosso, o Sistema Estadual de Unidades de Conservação deve ser implantado pelo poder público estadual, na forma do regulamento, visando à efetiva proteção de espaços territoriais, para manter e utilizar racionalmente o patrimônio biofísico e cultural de seu território (art. 32). Assim foi que o poder público, pela Lei Estadual n. 9.502, de 14.01.2011, e demais normas estabelecidas pelo Conselho Estadual de Meio Ambiente, fixou os critérios de uso, ocupação e manejo dessas áreas, sejam elas públicas ou privadas, vedadas quaisquer ações ou atividades que comprometam ou possam vir a comprometer os atributos e características especialmente protegidos (Código Estadual Ambiental, art. 33).

As Unidades de Conservação Federais em Mato Grosso, localizadas no bioma Amazônia são: Estação Ecológica do Iquê Juruena, em Juína, criada pelo Decreto nº 86.061/81, com 200.000 ha; Parque Nacional de Juruena, em Apiacás,

\footnotetext{
Embora legalmente prevista como de Uso Sustentável as RPPNs possuem características do grupo de Proteção Integral e são criadas por iniciativa dos proprietários das áreas interessados em sua preservação. Não serão, por isso, consideradas nesta abordagem.
}

Novos Cadernos NAEA, v. 16, n. 1, Suplemento, p. 221-246, jun. 2013 
Nova Bandeirantes e Cotriguaçu, no estado de Mato Grosso; Apuí e Maués, no estado do Amazonas, criado por Decreto $\mathrm{s} / \mathrm{n}^{\circ}$, de 05.06.2006, com área total de 1.957.000,00 ha, sendo 1.175.258,53 ha em Mato Grosso, e Parque Nacional dos Campos Amazônicos, em Colniza e estados do Amazonas e Rondônia, criado pelo Decreto s $/ \mathrm{n}^{\circ}$, de 21.07.2006, com área total de 873.570,00 ha, sendo 5.418,36 ha em Mato Grosso.

Sobre a Estação Ecológica do Iquê, é importante observar que ela tem 98\% de sua área sobreposta à Terra Indígena Enawene Nawe, e que o dispositivo legal que a criou foi revogado duas vezes, pelo Decreto $n^{\circ}$ 87.222, de 31.05.1982, e pelo Decreto $\mathrm{s} / \mathrm{n}^{\circ}$, de 02.10.1996. Entretanto, organismos governamentais e não governamentais continuam reconhecendo a existência dessa Estação Ecológica, mesmo porque pelo art. 225, III, da CF, os espaços territoriais e seus componentes a serem especialmente protegidos somente poderão ser alterados ou suprimidos através de lei, vedada qualquer utilização que comprometa a integridade dos atributos que justifiquem sua proteção.

As Unidades de Conservação Estaduais em Mato Grosso, localizadas no bioma Amazônia, com exceção das Reservas Particulares do Patrimônio Natural, são: Reserva Ecológica de Apiacás, criada pela Lei nº 6.464, de 22.06.1994, com 100.000 ha; Reserva Ecológica do Culuene, em Paranatinga, criada pelo Decreto $\mathrm{n}^{\circ}$ 1.387, de 10.01.1989, com 3.900 ha; Reserva Extrativista Guariba-Roosevelt, em Aripuanã e Colniza, criada pela Lei no 7.164, de 23.08.1999, com 138.092 ha; Parque Estadual Serra de Santa Bárbara, em Pontes e Lacerda e Porto Esperidião, criado pela Lei n 7.165, de 23.08.1999, com 120.092,12 ha; Parque Estadual Serra de Ricardo Franco, em Vila Bela da Santíssima Trindade, criado pelo Decreto n 1.796, de 04.11.1997, com 158.620,85 ha; Estação Ecológica do Rio Madeirinha, em Colniza, crida pela Lei no 7.163, de 23.08.1999, com 13.682,96 ha; Estação Ecológica do Rio Roosevelt, em Colniza, criada pela Lei no 7.162, de 23.08.1999, com 96.168 ha; Estação Ecológica do Rio Ronuro, em Nova Ubiratã, criada pelo Decreto $n^{\circ}$ 2.207, de 23.04.1998, com 102.000 ha; Parque Estadual do Cristalino I, em Alta Floresta e Novo Mundo, criado pelo Decreto n ${ }^{\circ}$ 1.471, de 09.06.2000, com 66.900 ha; Parque Estadual do Cristalino II, em Novo Mundo, criado pelo Decreto $n^{\circ}$ 2.628, de 30.05.2001, com 118.000 ha; Parque Estadual do Xingu, em Santa Cruz do Xingu, criado pela Lei no 8.054, de 29.12.2003, com 95.024,84 ha; Parque Estadual Igarapés do Juruena, em Colniza e Cotriguaçu, criado pelo Decreto no 5.438, de 12.11.2002, com 227.817 ha; Estação Ecológica Rio Flor do Prado, em Aripuanã, criada pelo Decreto no 2.124, de 09.12.2003, com 8.517 ha, e Parque Estadual Tucumã, em Colniza, criado pela Lei no 5.150, de 23.02.2005, com $80.944,71$ ha. 
No tocante às unidades de conservação municipais, no bioma Amazônia, são: Parque Natural Municipal Alto da Boa Vista, em Tangará da Serra, criado pelas Leis nº1.070, de 19.05.1995 e n 1.756, de 23.05.2001, com 9.34 ha; Parque Natural Municipal Ilto Ferreira Coutinho, em Tangará da Serra, criado pelas Leis $\mathrm{n}^{\mathrm{o}}$ 1.082, de 02.07.1995 e no 1.756, de 23.05.2001, com 11,77 ha; Parque Natural Municipal do Distrito do Progresso, em Tangará da Serra, criado pelas Leis $\mathrm{n}^{\circ}$ 1.369, de 13.11.1997 e no 1.756, de 23.05.2001, com 0,97 ha; Parque Florestal de Cláudia, em Cláudia, criado pela Lei no 266, de 16.12.1996, com 20,97 ha, e Parque Ambiental de Juína, em Juína, criado pelos Decretos n 1.657/96 e no. 060/2001, com 30,80 ha.

Em que pese o rol de unidades de conservação existentes no Estado, Mato Grosso é, ainda, o estado com o menor número de áreas protegidas (apenas 4,6\% de seu território) comparativamente aos demais estados amazônicos (VERÍSSIMO et. al., 2011, p. 17), cabendo ressaltar que parte das UCs citadas estão protegidas apenas "no papel”, o que pode comprometer a integridade dos atributos que justificaram a sua proteção.

Por isso mesmo, analisar os riscos e desafios à conservação e preservação dessas áreas pressupõe identificar os principais problemas socioambientais que as atingem e, eventualmente, as impedem de realizar seu fim precípuo de proteção.

Nesse sentido, este artigo busca identificar os problemas que enfrentam e os conflitos socioambientais associados à implantação e gestão das unidades de conservação (federais e estaduais) instituídas no estado de Mato Grosso na área do bioma Amazônia.

O que se constata, em linhas gerais, é que essas áreas, embora legalmente protegidas "no papel", enfrentam uma série de ameaças que colocam em risco as suas peculiaridades ecológicas. São riscos institucionais, além de agressões originadas em seu entorno. Podem ser citados como exemplo dessas ameaças a própria expansão do agronegócio, passando pela grilagem institucionalizada de terras públicas, o reassentamento de ocupantes não índios em terras indígenas, o conflito entre povos e comunidades tradicionais e unidades de conservação criadas em seu espaço, e, ainda, como um problema potencial, a própria implementação do novo Código Florestal, que coloca em risco áreas tradicionalmente protegidas.

Desse modo, constata-se que o conjunto de áreas que têm amparo legal e formam o sistema de proteção dos recursos naturais do país, compõe um sistema extenso e complexo, entretanto frágil e, em muitos casos, ineficaz, não por falta de leis, normas, regras, princípios, instituições e instrumentos, mas em função principalmente da falta de estrutura dos órgãos públicos, da superposição de atividades dos organismos governamentais, das lacunas que a legislação permite e, sobretudo, da forma como vêm sendo geridas essas áreas. 
Cumpre assinalar que dentre os problemas identificados, que serão examinados neste artigo, destacam-se: o avanço do desmatamento, com a expansão da fronteira agrícola; a atividade madeireira ilegal; a falta de políticas consistentes para consolidação das UCs criadas e sua efetiva proteção, o que inclui propostas de redução dessas áreas. Esses problemas estão associados a um contexto histórico que marcou, e ainda marca, o processo de colonização da região, conforme será abordado no item seguinte.

\section{A FRONTEIRA AGRÍCOLA: CONTEXTUALIZAÇÃO}

Entendendo que os problemas ambientais são formas de conflitos sociais que envolvem interesses, sentidos e fins, na relação homem e ambiente, tem-se que os conflitos ambientais configuram-se quando os atores sociais defendem lógicas distintas para a gestão dos bens coletivos de uso comum. Em se tratando da Amazônia Legal, a atuação desses atores está ligada ao processo de colonização da região.

A criação da Amazônia Legal está relacionada ao processo de desenvolvimento, ocupação e da integração dessa região às redes e fluxos que norteavam a política desenvolvimentista definida a partir das transformações econômicas ocorridas em meados da década de 1970, quando o mundo enfrentava a chamada "crise do petróleo" e o Brasil iniciava a grande luta contra a rápida elevação do nosso endividamento externo (SETTI, 2005). Naquela fase, o interesse econômico governamental residia na exportação de tudo que fosse possível vender. Assim, todos os benefícios dirigiam-se aos produtos que tinham mercado no exterior, como soja e laranja; ou que poderiam diminuir a despesa com o petróleo, como é o caso da cana-de-açúcar, produtora de álcool combustível, em prejuízo daqueles produtos voltados exclusivamente para o mercado interno de alimentos, como arroz, feijão, mandioca ou que abasteciam indústrias não exportadoras, como milho e algodão.

O resultado dessa política estimulou a entrada de dólares no Brasil, mas trouxe uma séria consequência para toda a estrutura agrária do país, que permanece até hoje: aumentaram as áreas exploradas com cultivos de exportação, utilizando, com essas lavouras, os melhores solos; diminuíram as áreas voltadas para a produção de alimentos, utilizando solos de pior qualidade e em regiões onde as terras são menos valorizadas. Tais medidas elevaram os custos dos alimentos. Diminuindo as áreas cultivadas e os investimentos, diminuiu a quantidade produzida e, como são cultivados longe dos grandes centros de 
consumo, aumentou o custo do transporte. A elevação dos preços dos alimentos contribuiu para o aumento da inflação e produziu uma queda na qualidade da alimentação da maior parte da população brasileira, cujo poder aquisitivo não acompanhou o aumento dos preços. Ademais, a inserção do país no contexto da globalização significou, entre outros aspectos, a abertura do mercado brasileiro às importações dos mais diversos bens, necessários ou não; então, passamos a gastar quantias excessivas de dólares, além de continuarmos pagando o serviço da dívida externa. Por isso, a agricultura de exportação continuou recebendo benefícios, em detrimento do cultivo de alimentos, que permaneceu com o preço elevado.

Assim, desde a década de 1970, as áreas do Centro-Oeste e Norte são vistas como uma possibilidade para a exploração da monocultura, fomentada por meio de incentivos fiscais industriais e políticas de assentamento rural. A política de assentamento é, inclusive, anterior, pois desde o final dos anos 1940, com a crise da borracha, o governo de Mato Grosso, com o apoio do governo federal, incentivou a colonização das regiões norte e médio norte do estado. Para isto, criou políticas que foram implementadas com a justificativa de tirar as regiões do isolamento em que se encontravam devido às dificuldades de acesso, e integrálas à economia do Estado, pelo desenvolvimento de atividades agroextrativistas.

Nesse período, a região foi alvo de políticas de colonização de ordem oficial e privada. As primeiras previam a implantação de comunidades agrícolas formadas por lotes pequenos, reservados a antigos seringueiros, garimpeiros e pequenos produtores agrícolas. As políticas privadas visavam à venda ou concessão de terras para pequenos, médios e grandes agricultores para a formação de novos núcleos populacionais e agrícolas. Mais tarde, a abertura de novas estradas e a expansão da fronteira agrícola para a região Centro-Oeste do país propiciaram a especulação destas terras por parte de empresas imobiliárias e, mais recentemente, a partir de meados de 1990, a agricultura de grãos cresceu rapidamente, inclusive em áreas tradicionalmente dominadas pela produção de alimentos básicos e extrativismo. Tal movimento leva a uma reorganização e reorientação no uso e posse desses territórios. O processo de expropriação de pequenos produtores (proprietários e não proprietários), antes engendrado pela pecuária, é retomado com força pelo grande capital, com apoio integral do governo (LOUREIRO, 2009), para fomento do agora chamado agronegócio.

Nesse contexto, o cenário é de uma área de mais de 5 milhões de $\mathrm{km}^{2}$ (dois terços do Brasil), a Amazônia Legal, caracterizada por um mosaico de ecossistemas com significativas diferenças tanto em termos de estrutura e interações de comunidades e populações naturais e ocorrência e abundância de

Novos Cadernos NAEA, v. 16, n. 1, Suplemento, p. 221-246, jun. 2013 
espécies da flora, fauna, fungos e microbiota (ISA, 2009), e os atores são seus aproximadamente 24,7 milhões de habitantes (IBGE, 2010), dentre os quais mais de 250 mil indígenas pertencentes a mais de 170 etnias (VERÍSSIMO et. al., 2011, p. 43) e diversas comunidades extrativistas tradicionais, como seringueiros, castanheiros, pescadores artesanais, quebradeiras de coco de babaçu, dentre outras. Vivem aí também mais de 350 comunidades remanescentes de quilombos e das comunidades tradicionais que chegaram a esse território em diferentes épocas e movidas por diferentes necessidades. Somam-se hoje, ainda, populações que mais recentemente passaram a ocupar a região, com variadas formas de produção, de pequenos produtores rurais a grandes empresas do agronegócio (PINTO, 2008, p. 83-106).

Frente a essas características, a imposição de modelos de programas de desenvolvimento e políticas econômicas como as de fomento ao agronegócio, frise-se, nesse cenário e para essa população local, é fator de conflito, na medida em que permite uma produção que implica na acelerada degradação dos recursos naturais; reduz drasticamente a diversificação produtiva e evidencia, ao mesmo tempo, uma incapacidade de viabilizar economicamente a maioria dos agricultores, sobretudo os familiares, e uma capacidade de avançar sobre áreas apropriadas ou não, em termos de aptidão agrícola, permitidas ou não, quando considerada a legislação ambiental para intensificar a produção, a fim de acompanhar as necessidades do mercado (SIMONIAN, 2010, p. 25).

O primeiro reflexo disso é o desmatamento. De acordo com o Instituto Nacional de Pesquisas da Amazônia (INPA), há relação entre o desmatamento e a economia, pois fatores como crédito rural, taxas de juros, índice de inflação e preço da terra são determinantes para o aumento ou redução do desmatamento (FEARNSIDE, 2005, p. 113-123), demonstrado que a criação de gado em médias e grandes propriedades e a expansão do agronegócio têm como consequência clara o desmatamento, além da perda de produtividade, mudanças no regime hidrológico, perda de biodiversidade e emissões de gases de efeito estufa (NOBRE, 2008, p. 7-17). Conforme dados do Instituto Nacional de Pesquisas Espaciais (INPE) (MINISTÉRIO..., 2012), o desmatamento da floresta amazônica em Mato Grosso, no ano de 2011, correspondeu a uma área de $1.120 \mathrm{~km}^{2}$, perdendo apenas para o Pará, cuja área desmatada foi de $3.008 \mathrm{~km}^{2}$. Note-se que a floresta amazônica no Pará (INPE, 2012), abarca uma área de $883.886 \mathrm{~km}^{2}$, enquanto que em Mato Grosso é de $315.273 \mathrm{~km}^{2}$.

Segundo levantamento feito pelas organizações Imazon e ISA, uma parte significativa desse desmatamento se deu em áreas legalmente protegidas: 
O desmatamento acumulado até julho de 2009 nas áreas florestadas da Amazônia Legal foi de $735.373 \mathrm{~km}^{2}$. Deste total, nas áreas de floresta no interior das Áreas Protegidas - isto é, hoje protegidas por Unidades de Conservação e Terras Indígenas - foi registrado o corte de $25.739 \mathrm{~km}^{2}$, ou seja, 3,5\% de todo desmatamento ocorrido na região (VERÍSSIMO et. al., 2011, p. 60).

Além da expansão do agronegócio, existem outros fatores que geram conflitos na Amazônia Legal. Nesse momento, a discussão sobre o reconhecimento de terras indígenas, como a ampliação da reserva indígena Kayabi, de 117 mil ha para 1,053 milhão de hectares entre os municípios de Apiacás (MT) e Jacareacanga (PA), traz à tona o desmatamento que ocorre nessa área, e o conflito entre índios e produtores rurais que adquiriram a terra por meio de projetos de colonização, além do conflito de interesses daqueles que pretendem explorar a jazida de calcário existente em Apiacás, as usinas hidrelétricas em fase de licitação e o projeto de construção de uma hidrovia. Entre áreas demarcadas como terra indígena ou pertencentes a comunidades locais e que, igualmente, são unidades de conservação, o conflito também existe, e novamente a política estatal interferiu para esse resultado.

Além disso, como fator agravante que impulsiona o desmatamento e a grilagem de terras públicas, incluindo as áreas protegidas, é a atividade madeireira feita à margem da lei. Ainda segundo a pesquisa conduzida pelo Imazon e ISA:

A atividade madeireira ilegal exerce forte pressão sobre as Áreas Protegidas da Amazônia, principalmente em áreas de fácil acesso por estradas e rios navegáveis (Barreto et al., 2005). Se realizada sem manejo, a exploração madeireira afeta severamente a biodiversidade, interferindo no equilíbrio entre espécies, animais e vegetais. E há impactos negativos associados ao acesso às árvores selecionadas para derrubada e ao arraste das toras. Mas a maior pressão, de fato, é exercida pela extração predatória que tem penetrado nas UCs e TIs. Para ser legal, a extração de madeira deve constar do plano de manejo e obter licença do órgão ambiental competente. E só é possível em algumas UCs de Uso Sustentável e TIs. Em UCs de Proteção Integral, a atividade sempre é ilegal (VERÍSSIMO et. al., 2011, p. 67).

Esse problema se agrava quando se constata a ausência do Estado nas áreas de conflito e a inexistência de políticas públicas consistentes, que possam garantir a demarcação e a gestão eficiente das UCs criadas. Falta vontade política, faltam recursos humanos e materiais, o que torna essas unidades de conservação áreas especialmente "des"protegidas.

Por isso mesmo existem inúmeras iniciativas visando reduzir ou suprimir áreas legalmente protegidas. Estudo do Imazon realizado em 2010 analisou 
37 propostas formais para alterar 48 Áreas Protegidas da Amazônia: 25 UCs estaduais, 16 UCs federais e 7 TIs. A maioria (68\%) das iniciativas ocorreu entre 2005 e 2010. Segundo levantamento conduzido pela citada organização:

As alterações foram propostas por meio de projeto legislativo - leis ou decretos, projetos de lei ou de decretos em tramitação - (em 69\% das Áreas Protegidas estudadas); ZSEE (Zoneamento Socioeconômico-Ecológico) do Estado de Rondônia (25\%); ação judicial (19\%); decreto executivo (4\%) e portaria (4\%). Até 15 de julho de 2010, 24 propostas $(65 \%$ do total) foram concluídas e 13 estavam inconclusas. Dos casos concluídos, $7 \%$ resultaram na manutenção do tamanho original das Áreas Protegidas $\left(114.124 \mathrm{~km}^{2}\right.$ ) enquanto $93 \%$ resultaram em sua supressão (perda da proteção legal), num total de $49.506 \mathrm{~km}^{2}$. [...] Os projetos legislativos somaram $22.601 \mathrm{~km}^{2}$ ou $46 \%$ da área total suprimida. Desses projetos legislativos, $82 \%$ eram estaduais. Rondônia foi o estado com mais Áreas Protegidas alteradas (21), sendo 7 UCs reduzidas e outras 14 extintas. Em seguida aparece Mato Grosso com 4 UCs estaduais reduzidas (ARAÚJO; BARRETO, 2010, p. 6).

Esses dados demonstram que mesmo as unidades de conservação já criadas seguem sob ameaça e que, ademais, não existe nenhuma garantia de que as mesmas gozarão da proteção que a legislação lhes confere. Ou seja, embora tenhamos algumas experiências históricas de gestão e recuperação de áreas de interesse ambiental, a proteção do meio ambiente é tema que polariza; e o debate em torno do novo Código Florestal evidencia que a correlação de forças não é favorável à consolidação dessas áreas legalmente protegidas.

A literatura que discute a história da política ambiental brasileira demonstra que os primeiros registros de inquietações com o ambiente ocorreram em 1658, no Rio de Janeiro. Naquele ano houve ações da sociedade pela preservação da flora em regiões de mananciais, pois a degradação ameaçava o abastecimento de água potável da cidade (BRITO, D.M.C., 2010, p. 37-57). A preocupação era com a qualidade da água servida às populações urbanas. A preocupação com a proteção da natureza no Brasil, até este período, surgiu das necessidades que a sociedade e o poder público tinham com a manutenção dos recursos naturais para o desenvolvimento das cidades. Preocupação refletida na Constituição Federal de 1934, que definiu como competência da União e dos Estados a proteção das belezas naturais e dos monumentos de valor histórico ou artístico do país. Esta determinação concedeu à natureza o valor de patrimônio nacional, devendo o poder público ser responsabilizado pela sua preservação e fiscalização. A deliberação indicou a concepção de proteção da natureza a partir da visão preservacionista, sem a presença humana. 
A primeira área efetivamente criada com objetivo explícito de proteção legal da natureza ocorreu em 1896, o Horto Botânico da cidade de São Paulo, instituído pelo governo de São Paulo. O movimento de proteção legal de áreas naturais prosseguiu no início do século XX, quando foram criadas duas estações biológicas, no Rio de Janeiro e em São Paulo. Nessas áreas não era permitida a presença humana, o que somente confirmava a tendência de estabelecer espaços com objetivo de proteção integral, sem considerar as populações locais (BRITO, 2000).

Embora a conservação ambiental na Amazônia por meio da criação de áreas especialmente protegidas seja bem mais recente, a tendência de desconsideração da população local e indígena prosseguiu e teve início com a criação da primeira Unidade de Conservação da Amazônia Legal, o Parque Nacional do Araguaia (TO), em 1959. O parque abrangia toda a Ilha do Bananal, com $20.000 \mathrm{~km}^{2}$. Alterações de limite posteriores reduziram a área da UC para $5.577 \mathrm{~km}^{2}$, para excluir a sobreposição com o Parque Indígena do Araguaia (VERÍSSIMO et. al. 2011, p. 22).

Nesse cenário de criação de espaços territoriais protegidos, sem levar em consideração a população, bem como de mudança de políticas públicas voltadas para a colonização, uma reorganização produtiva e crescente expropriação de áreas de pequenos produtores para grandes empreendimentos, a exclusão das populações locais - ribeirinhos, caboclos, índios, quilombolas e amplas camadas urbanas da sociedade que não se integram às elites, é um dos traços fundamentais na formação social da Amazônia (LOUREIRO, 2009, p. 21). Essas populações são consideradas um entrave para o desenvolvimento e, por conseguinte, são alijadas dos processos que pretendem a modernização da região, bem como são escorraçados para as periferias urbanas, para liberarem as terras que habitam e trabalham, visando disponibilizar a riqueza natural que elas encerram, e assim beneficiar aqueles que supostamente sabem e podem tirar delas melhor proveito econômico. Obviamente, há resistência, e o processo de exclusão e dominação da Amazônia é conflituoso, chegando à violência.

Os conflitos, nesse segundo aspecto, refletem não só a luta pela terra, mas a desigualdade social e a miséria, indicando que nessa região do Brasil pouco se tem conseguido melhorar, em relação à média nacional. A situação da região é crítica nos casos da pobreza, da incidência de malária, Aids, mortalidade materna e do saneamento básico. Os avanços também são tímidos na busca da igualdade entre os gêneros. Além disso, a região tem altos índices de violência (CALENTANO; SANTOS; VERÍSSIMO, 2010). Há disparidade dos indicadores entre as zonas urbanas e rurais, e os povos indígenas e demais populações tradicionais enfrentam grandes desafios para assegurarem o seu bem-estar.

Novos Cadernos NAEA, v. 16, n. 1, Suplemento, p. 221-246, jun. 2013 


\section{POLÍTICAS PÚBLICAS COM IMPACTOS NA BIODIVERSIDADE}

Cabe aos governos federal e estadual, com base na Convenção sobre Diversidade Biológica (CDB), dirimir esses conflitos de interesse, por meio da implementação de políticas públicas coerentes de acesso aos recursos da biodiversidade, reconhecendo os direitos dos povos indígenas e comunidades tradicionais aos recursos existentes em seus territórios, bem como ao conhecimento que tais populações têm desenvolvido ao longo dos séculos sobre eles, sem destruir a natureza (ARANTES, 2002).

As políticas de ocupação da Amazônia brasileira remontam à colonização europeia, a partir do século XVI. Além do ciclo da borracha, em resposta à seca de 1932, quando o governo Getúlio Vargas introduziu a imagem do sertanejo como um bandeirante novo, destinado a povoar os "espaços vazios" da nação, onde é implantado um programa de emergência para lidar com o enorme déficit de borracha nos Estados Unidos no contexto da Segunda Guerra Mundial, temos, nessa região, a implementação de diversos outros programas e projetos.

A criação da Fundação Brasil Central, no governo Getúlio Vargas, teve o objetivo de explorar e mapear a região amazônica, para efetivar projetos de colonização e interligá-la ao resto do país, sendo estabelecido na Constituição Federal, em 1946, o Plano de Valorização Econômica da Amazônia. Para executar esse plano, foi instituída a Superintendência do Plano de Valorização Econômica da Amazônia (SPVA), com o objetivo de criar um conjunto de serviços e empreendimentos para incentivar a melhoria nos padrões sociais e o desenvolvimento econômico da região amazônica, bem como de todo o país.

Em continuidade às políticas voltadas para a integração nacional, e com a transferência da capital federal para o centro do país, inicia-se a construção de rodovias, como a Belém-Brasília (BR-010), estabelecendo um inédito eixo SulNorte que, a partir da articulação com vias secundárias, permitiu o acesso e a exploração de áreas remotas da porção oriental da floresta amazônica.

Com o objetivo de acelerar o desenvolvimento econômico e a ocupação humana na região, dentro da nova dimensão ideológica assumida pelo regime militar, na qual a região amazônica representava um vazio demográfico que deveria ser ocupado a qualquer custo, foi criada a Superintendência do Desenvolvimento da Amazônia (SUDAM), em substituição à antiga SPVA.

Também a partir dessa lógica de implementação na região amazônica do processo de colonização e desenvolvimento da região, foi instituído o Programa de Integração Nacional (PIN), tendo como objetivo principal incentivar as atividades econômicas e a colonização de grandes extensões de terra na região, 
tendo sido implementados, a partir desse, também o Programa Polamazônia e o Programa Grande Carajás.

Buscando a construção de infraestrutura, na forma de portos, aeroportos e, principalmente, na construção de estradas que atravessariam a floresta, foram construídos a Cuiabá-Porto Velho (BR-364), a Transamazônica (BR-230) e a Cuiabá-Santarém (BR-163).

Outro marco dentro dessa lógica de colonização da Amazônia foi a criação do Instituto Nacional de Colonização e Reforma Agrária (INCRA), criado com a com a missão prioritária de realizar a reforma agrária, manter o cadastro nacional de imóveis rurais e administrar as terras públicas da União.

Outra política para a Amazônia, que contou com grandes críticas no tocante a seus resultados e os impactos causados a partir de sua implantação, foi o Programa Integrado de Desenvolvimento do Noroeste do Brasil (Polonoroeste), executado com recursos do governo brasileiro e do Banco Mundial, abrangendo a área de influência da rodovia BR-364, entre Cuiabá (MT) e Porto Velho (RO), tendo como objetivo principal o incentivo às atividades econômicas e à colonização de grandes extensões de terra.

$\mathrm{Na}$ sequência, o Programa Agropecuário e Florestal de Rondônia (Planafloro), implementado no estado de Rondônia, com financiamento do Banco Mundial (BIRD), concebido como um programa sucessor do Polonoroeste e objetivando implantar uma abordagem mais aperfeiçoada para o manejo, a conservação e o desenvolvimento dos recursos naturais.

Também financiado pelo Banco Mundial, o Projeto de Desenvolvimento Agroambiental do Estado de Mato Grosso (Prodeagro) teve como objetivo promover o desenvolvimento socioeconômico da população do estado de Mato Grosso, buscando estabelecer o equilíbrio entre o binômio ocupação e preservação.

Mais recentemente, já no âmbito de governança do Ministério do Meio Ambiente (MMA), na busca de um foco mais voltado para a questão da sustentabilidade, foi proposto o Plano BR-163 Sustentável, como plano estratégico de desenvolvimento regional referenciado no Plano Amazônia Sustentável (PAS), e que tem como objetivo promover o desenvolvimento sustentável da região de influência da rodovia BR-163.

O Plano Amazônia Sustentável (PAS), também liderado pelo Ministério do Meio Ambiente, foi instituído como objetivo principal de promover o desenvolvimento sustentável da Amazônia brasileira, mediante a implantação de um novo modelo pautado na valorização de seu enorme patrimônio natural e no aporte de investimentos em tecnologia e infraestrutura, voltado para a

Novos Cadernos NAEA, v. 16, n. 1, Suplemento, p. 221-246, jun. 2013 
viabilização de atividades econômicas dinâmicas e inovadoras, com a geração de emprego e renda, compatível com o uso sustentável dos recursos naturais e a preservação dos biomas, visando à elevação do nível de vida da população.

Mais recentemente, o Decreto $n^{\circ} 7.794$, de 20.8.2012, instituiu a Política Nacional de Agroecologia e Produção Orgânica (PNAPO), tendo em vista a Lei $n^{\circ} 10.711 / 2003$, sobre o Sistema Nacional de Mudas, e a Lei no ${ }^{\circ} 10.831 / 2003$, sobre a agricultura orgânica, mas com o objetivo expresso de integrar, articular e adequar políticas, programas e ações indutoras da transição agroecológica e da produção orgânica e de base agroecológica. No art. $2^{\circ}$ do Decreto, esses conceitos são estabelecidos. Assim, entende-se por produção de base agroecológica aquela que buscar otimizar a integração entre capacidade produtiva, uso e conservação da biodiversidade e dos demais recursos naturais, equilíbrio ecológico, eficiência econômica e justiça social, bem como por transição agroecológica, o processo gradual de mudança de práticas e de manejo de agroecossistemas, tradicionais ou convencionais, por meio da transformação das bases produtivas e sociais do uso da terra e dos recursos naturais, que levem a sistemas de agricultura que incorporem princípios e tecnologias de base ecológica.

Os instrumentos do PNAPO elencados, sem prejuízo de outros, são: Plano Nacional de Agroecologia e Produção Orgânica (PLANAPO); crédito rural e demais mecanismos de financiamento; seguro agrícola e de renda; preços agrícolas e extrativistas, incluídos mecanismos de regulação e compensação de preços nas aquisições ou subvenções; compras governamentais; medidas fiscais e tributárias; pesquisa e inovação científica e tecnológica; assistência técnica e extensão rural; formação profissional e educação; mecanismos de controle da transição agroecológica, da produção orgânica e de base agroecológica e sistemas de monitoramento e avaliação da produção orgânica e de base agroecológica.

Sobre o PLANAPO, o art. $5^{\circ}$ do Decreto estabelece o seu conteúdo mínimo: diagnóstico; estratégias e objetivos; programas, projetos, ações; indicadores, metas e prazos e modelo de gestão do Plano. Esse plano deve ser elaborado em 180 dias, contados a partir da publicação do Decreto n ${ }^{\circ}$ 7.794/2012, pela Câmara Interministerial de Agroecologia e Produção Orgânica (CIAPO) (art. 9, I), composta por representantes de diversos ministérios. Para acompanhar e monitorar os programas e ações integrantes do PLANAPO, bem como propor alterações para aprimorar a realização dos seus objetivos, entre outras atribuições, criou-se também a Comissão Nacional de Agroecologia e Produção Orgânica (CNAPO), constituída por 14 representantes de órgãos e entidades do Poder Executivo federal e 14 representantes da sociedade civil. 
Desse modo, estão definidas as bases para a estruturação de uma política agroecológica. Contudo, um quadro normativo consistente e compatível com uma política de contenção de desmatamento e de desenvolvimento sustentável pressupõe a compatibilidade com outras leis e políticas transversais, pois, do contrário, seus objetivos podem ser confrontados por políticas e incentivos existentes em outros setores, especialmente aqueles que possam fomentar a expansão da agricultura e pecuária em áreas florestadas, como o que possibilitou a redução de áreas de preservação permanente, com a promulgação da Lei $\mathrm{n}^{\mathrm{0}} 12.651 / 2012$.

Essa preocupação com a posição dúbia do governo brasileiro foi exposta por Irigaray (2011), no sentido de que, ao mesmo tempo em que apresenta um ambicioso plano para reduzir as emissões de carbono, de outro lado, o governo não parece determinado a exercer uma política ambiental eficaz, "mantendo um orçamento pífio para os órgãos ambientais enquanto aposta em obras altamente impactantes como as da usina de Belo Monte, ou o asfaltamento das BRs 163 (Cuiabá/Santarém) e 319 (Manaus/Porto Velho), dentre outras" (IRIGARAY, 2011, p. 156-169).

De sorte que, sem a "vontade política", nem todos os instrumentos legais podem fazer frente à ação degradadora contínua e crescente sobre áreas de floresta, a fim de sustentar o desenvolvimento agropecuário nos moldes em que foi estabelecido e permanece.

No que se refere à Política de Unidades de Conservação, estudos indicam que especialmente na Amazônia, a criação de unidades de conservação tem contribuído significativamente para conter a expansão da fronteira agrícola e reduzir as taxas de desmatamento que seguem, ainda, elevadas.

Nesse contexto, o desafio continua sendo investir na consolidação e fiscalização das unidades de conservação já criadas, o que implica em disponibilizar recursos para demarcação, investir na elaboração de planos de manejo, na implantação de conselhos gestores dessas UCs, ou seja, na efetivação de governança ${ }^{3}$ para a gestão de áreas protegidas, visando envolver também a sociedade civil nessa tarefa, mesmo porque a Constituição Federal estabelece que a proteção do meio ambiente incumbe ao poder público e à coletividade. É oportuno o alerta no estudo realizado pelo Imazon e ISA:

\footnotetext{
A expressão governança tem sido frequentemente usada para expressar "a capacidade governativa em sentido amplo, envolvendo a garantia de continuidade e implementação de decisões, a capacidade de ação do Estado na execução efetiva de políticas públicas - entendidas como realização de metas coletivas, o que supõe que expressem demandas realmente colocadas pelos diferentes segmentos sociais. Refere-se aos instrumentos e procedimentos que garantem a participação no processo de tomada de decisões, da pluralidade de interesses e idéias existentes na sociedade" (BERNARDO, 2001).
}

Novos Cadernos NAEA, v. 16, n. 1, Suplemento, p. 221-246, jun. 2013 
As Áreas Protegidas não estão imunes a ameaças. O desmatamento, as estradas, a mineração, a exploração madeireira e a tentativa de desafetação de algumas áreas são exemplos de impactos diretos sobre as Áreas Protegidas. Outros fatores, como a caça, a grilagem, a agropecuária, a fragmentação e os potenciais impactos indiretos gerados por projetos de infraestrutura não foram abordados, mas também constituem sérias ameaças sobre essas localidades, indicando que a pressão sobre as Áreas Protegidas é maior do que a considerada no presente trabalho.

Para garantir a integridade das Áreas Protegidas é importante coibir usos e ocupações irregulares e o desmatamento, por meio da fiscalização local e monitoramento remoto, garantindo às populações locais seus direitos exclusivos. Os órgãos ambientais (federais e estaduais) e o Ministério Público podem contribuir com a fiscalização e o monitoramento a partir do investimento em novos recursos tecnológicos para aumentar a eficiência e transparência de suas ações, aliado a um programa de auditoria, capacitação e treinamento dos seus quadros de funcionários.

A escassez de recursos humanos e a insuficiência de recursos financeiros serão os grandes desafios dos próximos anos para a consolidação das Áreas Protegidas na Amazônia. Programas como o PPG7 e o Arpa são fundamentais para a consolidação das Áreas Protegidas. As fontes de financiamento de Áreas Protegidas devem ser ampliadas e os mecanismos de transferência de recursos devem ser transparentes, garantindo a alocação coerente do que é arrecadado, não apenas aos órgãos gestores, mas também de forma a fortalecer iniciativas sustentáveis e cadeias produtivas que envolvam saberes tradicionais das comunidades envolvidas (VERÍSSIMO et.al., 2011, p. 83).

Os desafios são enormes, mas os benefícios da conservação da Amazônia se destacam não apenas em função do valor e importância de sua rica biodiversidade, mas do papel que a floresta possui na modelação do clima em nosso país e no mundo.

\section{CONSIDERAÇÕES FINAIS}

Conhecida como a maior floresta tropical do mundo, a Amazônia tem tido sua biodiversidade explorada como um fator estratégico para a região e, em função do dinamismo das atividades vinculadas à exploração dos seus recursos naturais, face aos processos de ocupação mais recente, encontra-se ameaçada, principalmente pelo desflorestamento, queimadas e pelo avanço da fronteira agrícola.

Na região compreendida como Amazônia Legal, no estado de Mato Grosso, que apresenta um alto grau de urbanização, a maior influência relaciona-se à 
pressão antrópica causada pela mineração, desflorestamento, lavouras e pecuária. A expansão dessas atividades é resultado de planos e políticas de desenvolvimento adotados a partir da década de 1970, tais como o estabelecimento de corredores econômicos, representados pelas rodovias Cuiabá-Santarém, BR-070, BR-364, Ferronorte e hidrovias. Em consequência, houve o aumento da especulação fundiária, o uso e ocupação desordenada destas áreas, contribuindo para a fragmentação de habitats e perda de biodiversidade.

Nesse contexto, as vastas e diferentes tipologias, grupos e categorias de espaços legalmente protegidos, criados para atender às necessidades da sociedade, Estado e para ratificar diversos acordos, tratados e convenções adotados pelo Brasil, têm sua eficácia ainda discutível, diante dos conflitos socioambientais que se estabelecem nessas áreas, sem sinal de trégua, e dos indicadores de que a região não se desenvolve como deveria e, ainda, sofre com o agravamento da degradação ambiental.

Os níveis de proteção dessas áreas legalmente criadas encontram óbices em vários pontos, a começar pela construção histórica das políticas agrícola e ambiental brasileiras, a primeira baseada na monocultura intensiva e a segunda com pressupostos teóricos baseados nas concepções preservacionistas, seguidas pela própria formalização da legislação, com várias normas que baseiam o desenvolvimento de ações de comando e controle, a depender do aparelhamento estatal e do conjunto de órgãos gestores, envolvendo as três esferas de governo, que pode ter seu uso restringido nele próprio, ao articular políticas que continuam implementando o desenvolvimento nacional às custas dos recursos da floresta, e sem se desvencilhar dos antigos pressupostos.

Por isso mesmo, a definição de um arcabouço legal e a estruturação de um Sistema de Unidades de Conservação constituem apenas um passo na implementação de uma política consistente para o setor. Embora exista uma demanda legítima pela ampliação das unidades de conservação em nosso país, e a sua efetiva proteção, existem também interesses contraditórios que precisam ser superados ou harmonizados, o que pressupõe uma ação efetiva de governança.

Torna-se premente uma ampla rediscussão dessa política. Afinal, nós queremos assegurar uma especial proteção a determinados espaços territoriais representativos dos ecossistemas ainda existentes? Que tipos de unidades de conservação queremos?

Se reconhecermos a importância das unidades de conservação para a proteção da biodiversidade, ações concretas precisam ser executadas. Afinal, uma significativa parcela dessas áreas, mormente as de uso indireto, como os parques nacionais e estaduais, ainda não foi efetivamente implantada, permanecendo sem 
regularização fundiária, Planos de Manejo etc., e, por isso, sofrendo pressões antrópicas e descaracterização. Torna-se necessária, pois, uma ação conjunta do poder público e da sociedade civil, visando promover uma avaliação global da situação das unidades de conservação em nosso país e a definição de uma estratégia que permita a efetiva proteção desses espaços territoriais e, com eles, da biodiversidade.

\section{REFERÊNCIAS}

ARANTES, R.B. Ministério público e política no Brasil. São Paulo: Educ; Sumaré; Fapesp, 2002. (Série Justiça).

ARAÚJO, E.; BARRETO, P. Ameaças formais contra as Áreas Protegidas na Amazônia. Belém: Imazon, 2010. (Estado da Amazônia, n.16).

BERNARDO, M. Políticas públicas e sociedade civil. In: BURSZTYN, M. (Org.). A Difícil Sustentabilidade. Política energética e conflitos ambientais. Rio de Janeiro: Garamond, 2001.

BICUDO, C. E. de M.; SHEPHERD, G. J. Biodiversidade do Estado de São Paulo, Brasil: síntese do conhecimento ao final do século XX: Fungos Macroscópicos \& Plantas. In: JOLY, C. A.; BICUDO, C. E. (Orgs.). Biodiversidade do Estado de São Paulo, Brasil: síntese do conhecimento ao final do século XX. São Paulo: FAPESP, 1998. v. 2.

BRASIL. Congresso Nacional. Lei $\mathbf{n}^{\mathbf{0}}$ 5.173/1966. Dispõe sobre o Plano de Valorização Econômica da Amazônia; extingue a Superintendência do Plano de Valorização Econômica da Amazônia (SPVEA), cria a Superintendência do Desenvolvimento da Amazônia (SUDAM) e dá outras providências. Brasília, 1966.

BRASIL. Congresso Nacional. Lei Complementar no 31/1977.Cria o Estado de Mato Grosso do Sul, e dáoutras providências. Brasília, 1977.

BRASIL. Congresso Nacional. Lei $\mathbf{n}^{\mathbf{0}} \mathbf{9 . 9 8 5 / 2 0 0 0}$. Dispõe sobre a Política Nacional de Unidades de Conservação. Regulamenta o art. 225, \ 1, incisos I, II, III eVII da Constituição Federal, institui o SistemaNacional de Unidades de ConservaçãoNatureza e dá outras providências. Brasília, 2000.

BRASIL. Congresso Nacional. Lei no $\mathbf{~ 1 2 . 6 5 1 / 2 0 1 2 . ~ D i s p o ̃ e ~ s o b r e ~ a ~ p r o t e c ̧ a ̃ o ~ d a ~}$ vegetação nativa;altera as Leis $\mathrm{n}^{\underline{\text { os }}}$ 6.938, de 31 de agosto de1981, 9.393, de 19 de dezembro de 1996, e11.428, de 22 de dezembro de 2006; revoga as Leis nos 4.771, de 15 de setembro de 1965, e 7.754, de 14 de abril de 1989, e a Medida Provisória n⿳0 2.166-67, de 24 de agosto de 2001; e dá outras providências. Brasília, 2012. 
BRASIL. Congresso Nacional. Lei n $\mathbf{n}^{\mathbf{9}} \mathbf{9 . 9 8 5}$ /2000. Regulamenta o art. 225, S 1ㅜ, incisos I, II, III eVII da Constituição Federal, institui o VII da Constituição Federal, institui o SistemaNacional de Unidades de Conservação daNatureza e dá outras providências. Brasília, 2000.

BRASIL. Congresso Nacional. Constituição Federal. Capítulo VI - Do Meio Ambiente. Art. 225. Brasília, 1988.

BRASIL. Presidência da República. Decreto nº 86.061/81. Cria a Estação Ecológica do Iquê Juruena, no Estado de Mato Grosso. Brasília, 1981.

BRASIL. Presidência da República. Decreto s/nº, de 21.07.2006. Cria o Parque Nacional dos Campos Amazônicos, nos Estados do Amazonas, Rondônia e Mato Grosso.Brasília, 2006.

BRASIL. Presidência da República. Decreto nº 87.222, de 31 de Maio 1982. Cria as Estações Ecológicas do Seridó - RN, Serra das Araras - MT, Guaraqueçaba PR, Caracaraí - Território Federal de Roraima, e dá outras providências. Brasília, 1982.

BRASIL. Congresso Nacional. Lei $\mathbf{n}^{\mathbf{0}} \mathbf{1 . 8 0 6 / 1 9 5 3}$. Cria a Amazônia Legal. Rio de Janeiro, 1953.

BRASIL. Presidência da República. Decreto n⿳0.7.794, de 20.8.2012. Instituiu a Política Nacional de Agroecologia e Produção Orgânica. Brasília, 2012.

BRASIL. Congresso Nacional. Lei n ${ }^{\circ}$ 10.711, de5 de Agosto de 2003. Dispõe sobre o Sistema Nacional de Sementes e Mudas e dá outras providências. Brasília, 2003.

BRASIL. Congresso Nacional. Lei $\mathbf{n}^{\mathbf{0}}$. 10.831/2003, de 23 de Dezembro de 2003. Dispões sobre a agricultura orgânica e dá outras providências. Brasília, 2003.

BRITO, D. M. C. Áreas legalmente protegidas no Brasil: instrumento de gestão ambiental. Planeta Amazônia. Revista Internacional de Direito Ambiental e Políticas Públicas, Macapá, n. 2, p. 37-57, 2010.

BRITO, M. C. W. Unidades de Conservação: interações e resultados. São Paulo: FAPESP, 2000.

BURSZTYN, M. (Org.). A Difícil Sustentabilidade. Política energética e conflitos ambientais. Rio de Janeiro: Garamond, 2001.

CALENTANO, D.; SANTOS, D.; VERÍSSIMO, A. A Amazônia e os objetivos do Milênio 2010. Belém: Imazon, 2010. 
CAPOBIANCO, J. P. (Org.). Dossiê Mata Atlântica. Monitoramento participativo da Mata Atlântica. São Paulo: ISA, 2001.

CASTRO, E. M. R. Políticas de ordenamento territorial, desmatamento e dinâmicas de fronteira. Revista Novos Cadernos NAEA, Belém, v. 10, n. 2, p. 105-126, dez. 2007.

CASTRO, R. M. C. Biodiversidade do Estado de São Paulo, Brasil: síntese do conhecimento ao final do século XX: vertebrados. In: JOLY, C. A.; BICUDO, C. E. (Orgs.). Biodiversidade do Estado de São Paulo, Brasil: síntese do conhecimento ao final do século XX. São Paulo: FAPESP, 1998. v. 6.

CLÁUDIA. Câmara dos Vereadores. Lei no . 266, de 16.12.1996. Cria o Parque Florestal de Cláudia. Cláudia, 1996.

DIEGUES, A. O mito moderno da natureza intocada. São Paulo: Annablume, 2002.

DA SILVA, M. N. F.; RYLANDS, A. B.; PATTON, J. L. Biogeografia e conservação da mastofauna na Floresta Amazônica Brasileira. In: CAPOBIANCO, J.P.R.; VERÍSSIMO, A.; MOREIRA, A.; SAWYER, D.; SANTOS, I.; PINTO, L.P. (Eds.). Biodiversidade na Amazônia Brasileira: avaliação e ações prioritárias para a conservação, uso sustentável e repartição de benefícios. São Paulo: Instituto Socioambiental, 2001.

ENRIQUEZ, G. A trajetória tecnológica dos produtos naturais e biotecnológicos derivados na Amazônia. Belém: UFPA/Núcleo do Meio Ambiente, 2001.

FEARNSIDE, P. M. Desmatamento na Amazônia brasileira: história, índices e consequências. Revista Megadiversidade, Belo Horizonte, v. 1, n. 1, p. 113 123, jul. 2005.

FELFILI, J. M. Padrões de diversidade do Cerrado do Centro-Oeste brasileiro. In: ARAÚJO, E.L.; MOURA, A.N.; SAMPAIO, E.S.B.; GESTINARI, L.M.S.; CARNEIRO, J.M.T. (Eds.). Biodiversidade, conservação e uso sustentável da flora do Brasil. Recife: Universidade Federal Rural de Pernambuco, 2002.

IBGE-INSTITUTO BRASLEIRO DE GEOGRAFIA E ESTATÍSTICA. Geoestatísticas revelam patrimônio ambiental da Amazônia legal. 2010. Disponível em: <http://www.ibge.gov.br/home/presidencia/noticias/noticia_ visualiza.php?id_noticia=1887\&id_pagina=1>. Acesso em: 5 jul. 2012.

INPE-INSTITUTO NACIONAL DE PESQUISAS ESPACIAIS. Disponível em: <http://www.dpi.inpe.br/prodesdigital/prodesmunicipal.php>. Acesso em: 30 jun. 2012. 
ISA-INSTITUTO SOCIOAMBIENTAL. Laboratório de Geoprocessamento. 2009. Amazônia Brasileira 2009 (mapa). Edição especial Programa Áreas Protegidas da Amazônia (ARPA). Disponível em: <http://www.socioambiental. org/banco_imagens/pdfs/Amazonia2009_ISA_portuguesBaixa.pdf>. Acesso em: 5 jul. 2012 .

IRIGARAY, C. T. J. H. Transição para uma economia verde no direito brasileiro: perspectivas e desafios. Política Ambiental - Economia Verde: Desafios e oportunidades, Belo Horizonte, n. 8, p. 156-169, jun. 2011.

IRIGARAY, C. T. J. H. Aspectos constitucionais da proteção de unidades de conservação. Direito Ambiental em Debate, Rio de Janeiro, v. 2, p. 81-91, 2004.

JOLY, C. A.; BICUDO, C. E. (Orgs.). Biodiversidade do Estado de São Paulo, Brasil: síntese do conhecimento ao final do século XX. São Paulo: FAPESP, 1998. v. 2, 6.

JUÍNA. Prefeitura Municipal. Decretos n⿳. 1.657/1996 e n⿳0.060/2001. Cria o Parque Ambiental de Juína. Juina, 1996/2001.

LOUREIRO, V. R. A Amazônia no século XXI: novas formas de desenvolvimento. São Paulo: Empório do Livro, 2009.

MATO GROSSO. Assembleia Legislativa. Lei $\mathbf{n}^{\mathbf{0}} \mathbf{9 . 5 0 2}$, de 14 de Janeiro 2011. Institui o Sistema Estadual de Unidades de Conservação - SEUC, e dá outras providências. Cuiabá, 2011.

MATO GROSSO. Assembleia Legislativa. Lei Complementar $\mathbf{n}^{\mathbf{o}} \mathbf{3 8}$, de 21 de novembro de 1995. Dispõe sobre o Código Estadual do Meio Ambiente e dá outras providências. Cuiabá, 1995.

MATO GROSSO. Assembleia Legislativa. Lei $\mathbf{n}^{\mathbf{0}} \mathbf{. 6 . 4 6 4}$, de 22.06.1994. Cria a Reserva Ecológica de Apiacás. Cuiabá, 1994.

MATO GROSSO. Governo do Estado. Decreto n⿳0. 1.387, de 10.01.1989, Cria a Reserva Ecológica do Culuene. Cuiabá, 1989.

MATO GROSSO. Assembleia Legislativa. Lei $\mathbf{n}^{\mathbf{0}}$. 7.164, de 23.08.1999. Cria a Reserva Extrativista Guariba-Roosevelt. Cuiabá, 1999.

MATO GROSSO. Assembleia Legislativa. Lei $\mathbf{n}^{\mathbf{o}}$. 7.165, de 23.08.1999. Cria o Parque Estadual Serra de Santa Bárbara. Cuiabá, 1999.

MATO GROSSO. Governo do Estado. Decreto n ${ }^{\mathbf{0}}$. 1.796, de 04.11.1997. Cria o Parque Estadual Serra de Ricardo Franco. Cuiabá, 1997.

MATO GROSSO. Assembleia Legislativa. Lei $\mathbf{n}^{\mathbf{o}}$. 7.163, de 23.08.1999. Cria a Estação Ecológica do Rio Madeirinha. Cuiabá, 1999. 
MATO GROSSO. Assembleia Legislativa. Lei $\mathbf{n}^{\mathbf{0}}$. 7.162, de 23.08.1999. Cria a Estação Ecológica do Rio Roosevelt. Cuiabá, 1999.

MATOGROSSO. Governo do Estado. Decreto $\mathbf{n}^{\mathbf{0}} \mathbf{2}$ 2.207, de 23.04.1998. Cria aEstação Ecológica do Rio Ronuro. Cuiabá, 1998.

MATOGROSSO. Governo do Estado. Decreto $\mathbf{n}^{\mathbf{0}} \mathbf{. 1 . 4 7 1}$, de 09.06.2000. Cria o Parque Estadual do Cristalino I. Cuiabá, 2000.

MATOGROSSO. Governo do Estado. Decreto $\mathbf{n}^{\mathbf{0}} \mathbf{. 2 . 6 2 8}$, de 30.05.2001. Cria o Parque Estadual do Cristalino II. Cuiabá, 2001.

MATO GROSSO. Assembléia Legislativa. Lei n⿳o.8.054, de 29.12.2003. Cria o Parque Estadual do Xingu. Cuiabá, 2003.

MATOGROSSO. Governo do Estado. Decreto $\mathbf{n}^{\mathbf{0}} \mathbf{. 5 . 4 3 8}$, de 12.11.2002. Cria o Parque Estadual Igarapés do Juruena. Cuiabá, 2002.

MATOGROSSO. Governo do Estado. Decreto $\mathbf{n}^{\mathbf{0}} \mathbf{. 2 . 1 2 4}$, de 09.12.2003. Cria o Estação Ecológica Rio Flor do Prado. Cuiabá, 2003.

MATO GROSSO. Assembléia Legislativa. Lei $\mathbf{n}^{\mathbf{0}} \mathbf{.} \mathbf{5 . 1 5 0}$, de 23.02.2005. Cria o Parque Estadual Tucumã. Cuiabá, 2005.

MINISTÉRIO DA CIÊNCIA E TECNOLOGIA. Coordenação Geral de Observação da Terra. Projeto PRODES: monitoramento da floresta Amazônica por satélite. Disponível em: < http://www.obt.inpe.br/prodes/ > . Acesso em: 30 jun. 2012.

NOBRE, C. Mudanças climáticas e o Brasil - contextualização. Revista Parcerias estratégicas, Brasília, n. 27, Dez. 2008.

PINTO, L.F. Amazônia. In: RICARDO, B.; CAMPANILI, M. (Org.). Almanaque Brasil Socioambiental. São Paulo: Instituto Socioambiental, 2008, p. 83-106.

RICARDO, B.; CAMPANILI, M. (Org.). Almanaque Brasil Socioambiental. São Paulo: Instituto Socioambiental, 2008.

SETTTI, A. A. Caracterização da política agroambiental do Brasil. Relatório de Consultoria. 2005. Disponível em: <http://www.iicadesertification.org.br/ imagem/noticia/File/Testes/Relatorio_Setti.pdf>. Acesso em: 26 ago. 2012.

SILVA, J. A. da. Direito Ambiental Constitucional. São Paulo: Malheiros, 1994.

SIMONIAN, L. T. (Org.). Políticas públicas, desenvolvimento, conservação de recursos naturais e outros contextos sócio-ambientais no Amapá. Belém: NAEA/UFPA, 2010. 
TANGARÁ DA SERRA. Câmara dos Vereadores. Leis no 1.070, de 19.05.1995, e $\mathbf{n}^{\mathbf{o}}$ 1.756, de 23.05.2001. Cria o Parque Natural Municipal Alto da Boa Vista. Tangará de Serra, 1995/2001.

TANGARÁ DA SERRA. Câmara dos Vereadores. Leis nº 1.082, de 02.07.1995, e $\mathbf{n}^{\mathbf{0}}$ 1.756, de 23.05.2001. Cria o Parque Natural Municipal Ilto Ferreira Coutinho. Tangará da Serra, 1995/2001.

TANGARÁ DA SERRA. Câmara dos Vereadores. Leis no 1.369, de 13.11.1997, e $\mathbf{n}^{\mathbf{o}}$ 1.756, de 23.05.2001. Cria o Parque Natural Municipal do Distrito do Progresso. Tangará da Serra, 1997/2001.

VERÍSSIMO, A.; ROLLA, A.; VEDOVETO, M.; FUTADA, S. de M. Áreas Protegidas na Amazônia Brasileira: avanços e desafios. Belém: Imazon; São Paulo: ISA, 2011.

WILLINK, P.W.; CHERNOFF, B.; ALONSO, L.E.; MONTAMBAULT, R.; LOURIVAL, R. (Eds.). A biological assessment of the aquatic ecosystems of the Pantanal, Mato Grosso do Sul, Brasil. Washington, DC: Conservation International, 2000. (RAP Bulletin of Biological Assessment, 18). 